\title{
Domestic Tourism in COVID-19 Era: Travel Choice in Himalayas Correlates to Geographic Origin and Age
}

\author{
Chandramani Aryal \\ Department of Environmental Science, Padmakanya Multiple Campus, TU \\ aryal.mani@gmail.com \\ Prakash Chandra Aryal \\ Department of Environmental Science, Golden Gate International College, TU \\ Narayan Niraula \\ Saptagandaki Multiple Campus, Chitwan \\ Bina Ghimire \\ Central Department of Environmental Science, TU \\ Saroj Pokhrel \\ Environment Protection and Study Center (ENPROSC) \\ Ram Chandra Nepal \\ Environment Protection and Study Center (ENPROSC)
}

\section{Article History}

Received: 27 October 2021

Accepted: 4 December, 2021

\section{Keywords}

COVID-19, domestic tourism, geographic origin, pandemic, post pandemic recovery

Corresponding Editor

Ramesh Raj Kunwar

kunwar.dr@gmail.com

\section{Abstract}

COVID-19 pandemic and subsequent has created recession in the tourism industry on the global scale impacting the livelihood of the millions of people worldwide. Speedy recovery of the tourism industry is essential to ensure the development progress do not retard drastically due to this pandemic. As the world is severely affected by the COVID-19 pandemic and international tourism will take quite a bit longer time to recover, domestic tourism could be a way forward for the recuperation of the industry. Therefore, this article aims to understand the potential of domestic tourism to keep the momentum of tourism development, after the pandemic situation gets over. Data on general characteristics of the 
respondents and their attitude towards travel after restrictions are over were collected using online survey. Descriptive and regression analyses were used to understand the relationship between travel decisions and respondents' attributes. The travel decision was found significantly related to the age and geographic origin of the respondents indicating those who are less susceptible to infection are willing to travel sooner than other. Study indicates the expansion of tourism demand in relatively less popular destinations and diversified tourism products which might pose both the challenges and opportunities for tourism industry in post-COVID-19 situation. The findings of our study are expected to help in planning the post-pandemic recovery of the tourism industry in the country.

\section{Introduction}

Coronavirus disease (COVID-19) caused by Severe Acute Respiratory Syndrome Coronavirus 2 (SARS-CoV-2) was first reported by the World Health Organization (WHO) from Wuhan Province of China on December 31, 2019 (WHO 2020). The disease outbreak was declared as a global pandemic later on March 11, 2020 by the WHO (WHO 2020). The COVID-19 pandemic has affected various sectors of society, including tourism society (McKibbin \& Fernando 2020; Ruiz Estrada et al. 2020; UNWTO 2020). In the pre-pandemic situation, tourism was one of the major economic activities contributing nearly one-tenth of the global economic market, as indicated by both the share of Gross Domestic Product (GDP) and jobs created directly or indirectly (WTTC 2020a). However, after the COVID-19 pandemic, countries across the world adopted different response measures including travel restrictions (Chinazzi et al. 2020; Cohen \& Kupferschmidt 2020) which means that almost all the international flights were suspended, halting international tourism activities (Gössling et al. 2020). If we examine the past, during the SARS outbreak in 2003 and the economic recession of 2009/10, tourism activities had recovered within a short period of time once the impact was over (Gössling et al. 2020). However, the situation is quite different for now and the lag period is expected to extend more than that in the previously mentioned crises. In response, the tourism industry should be prepared with full functionality to welcome and accommodate tourists when the current pandemic ends and normalcy is restored. As domestic tourism is anticipated to resume prior to the convalescence of international tourism (Gössling et al. 2020), tourism industry need to focus on domestic costumers. Understanding the ways in which different social, geographic, and professional characteristics of tourists guide their decision about visiting or avoiding travel would be crucial to plan the restoration of tourism operations in the country.

Tourism contributes significantly to the Nepali economic sector, with a contribution of $7.5 \%$ in GDP and provision of 1.05 million direct and indirect jobs (WTTC 2020b). The share of tourism in the economic sector, both in the fronts of GDP and jobs, has increased gradually, except for the year 2015, where 
tourism declined by nearly $30 \%$ compared to the preceding year due to the Gorkha Earthquake. In the pre-COVID pandemic, the number of tourist visiting Nepal crossed one million for two consecutive years in 2018 and 2019 (MoTCA, 2020). Tourism was kept at the high priority by the Government of Nepal and they were conducting a promotional campaign to welcome at least 2 million international tourists in the year 2020 (Shrestha et al. 2020). Despite the explicit contribution of tourism to the economy and its acknowledgment as a tool to alleviate poverty at the national and local levels (Adler et al. 2013), most of the government's policies manifest that the government has taken tourism as synonymous with the activities of inbound tourists only. However, there are instances when there was a decline in international tourist arrival and internal tourism has been appreciable during the time of crises in Nepal (Upadhayaya et al. 2011). In developing countries, domestic tourism can be an important driver for sustainable development, but there is a need to explore the potential (Kabote et al. 2017). As such, the role of domestic tourism in the distribution of income and wealth has been largely ignored or are less prioritized throughout the world (Llorca-Rodríguez et al. 2020) including Nepal (Basnyat et al., 2020).

The Government of Nepal imposed different restrictions to contend the spread of COVID-19 in the country. Trekking permit issuance was constrained for some areas from March 11, 2020 for unforeseeable period, while on-arrival visas for the visitors were restricted from the following day. Later on, the lockdown was enforced in the country from March 24, suspending all the international flights and that impinged the tourism sector. Following the decision to impose lockdown in the country, tourism activities have been ceased (As of September 25, 2020).

Covid-19 has now appeared as a tourism demand crisis (Zenker \& Kock 2020) with tourism activities around the world ceased due to the global pandemic (Gössling et al. 2020). The impact of COVID-19 in tourism is expected to be capable of altering future tourism paradigms (Hall et al. 2020). For developing countries like Nepal where the sector is in a vulnerable situation despite of constant growth, it is essential to find a way out immediately. Globally, there has been a recent upsurge in descriptive and case study dominated research on the impacts of COVID-19 in tourism, but they are of no managerial implications to respond to the current pandemic (Zenker \& Kock 2020). COVID-19 pandemic has highlighted the interwoven nature of the social, ecological and environmental problems and the need to address those in a holistic manner (Rastegar et al., 2021). In tourism industry, business as usual scenario will not be sufficient to address the problem and we need to make industry more resilient by shifting our focus from international to quality domestic tourism (Hussain \& Fusté-Forné, 2021; Rastegar et al., 2021)\{“id”:”ITEM-2",'itemData”:\{“DOI”:"10.3390/ world2010009'”'abstract":"The current pandemic (Covid-19. Stimulation of the 
domestic tourism by government authorities and addressing the safety concerns of travellers by concerned stakeholders are equally important (Grančay, 2020). Most of studies on post pandemic tourism recovery are based on the perspectives of managers or regulators while the responses of potential visitors are largely ignored. Thus, there is a need for the research that helps to understand changes in tourist behavior in post-pandemic scenario. Effective tourism policy can be formulated when the factor affecting the driving and hindering factors of visit are well understood ( $\mathrm{Li}$ et al. 2016). Personal factors, such as motivation, fear, and attitudes, along with economic factors such as travel expenditure and leisure time, are important factors impacting travel decisions (Li et al. 2016). Although there are many research on the impacts of COVID-19 on the tourism industry, research on aspects of domestic tourism in Nepal is limited, which can offer policy guidance to drive the tourism sector to postpandemic recovery.

This study was designed to partially fill the literature gap in domestic tourism in Nepal. The aim of this study was to assess the potential of domestic tourism to keep the momentum of tourism activities in the country. The objectives were (1) to explore the willingness of domestic travelers to travel within the country immediately after the lockdown and other travel restrictions are withheld by the government and factors affecting the decision and (2) to understand how personal and social factors influence the choice of destinations. The research is expected to give policy guidance to the concerned stakeholders for targeting the relevant groups with tailored programs to inspire those groups to travel to different destinations.

\section{Materials and methods}

\section{Study area}

The study was carried out in the context of a south Asian country; 'Nepal', which has an area of $147,516 \mathrm{sq}$. km. Nepal is bordered by China in the north and by India in the rest of the directions. The country lies between the coordinates of $28.3949^{\circ} \mathrm{N}$ and $84.1240^{\circ} \mathrm{E}$. The shape of the country is roughly like a rectangle where the average length from east to west is $885 \mathrm{Km}$ and the average width from north to south is 193 $\mathrm{Km}$. While going from south to north of the country, there is an increase in elevation and landforms change from low plains to highlands. The aspect of biodiversity is strong for the country since it lies at the junction of Palaearctic and Indo-Malayan biogeographic realms (HMGN/MFSC 2002). On the basis of income, the country is one of the 47 Least Developed Countries (LDCs) (UN DESA 2018). Nepal, although an economically struggling landlocked country but is not less provided with touristic destinations (Thapa 2003, Bhattarai et al. 2005). The tourism of Nepal can be ascribed to nature, adventure, and culture (Sharma 2012). The northern part of the country has spectacular high Himalaya ranges, which possess the world's 
eight of the 14 highest peaks of the world. Next to the high Himalayas in the south, there lie beautiful mid-hills, Mahabharat range, valleys, lakes, and churiya ranges with extremely grand panorama in every direction. These mountainous regions offer attractions like snow-capped great Himalayan ranges, deep gorges, beautiful landscapes, beautiful forests, vast numbers of wild flora and fauna, preferable cool climatic conditions, mountain products, etc. for the visitors. Various mountain tourism activities, such as trekking, mountaineering, pony trekking, rock climbing, bird watching, bungee jumping, paragliding, mountain flight, cable car, rafting, kayaking, boating, swimming, and many more have been mesmerizing tourists in these regions. Annapurna range, Rara, Everest base camp, Manang, Mustang, Mardi Himal, Tilicho, Gosaikunda, Ilam, Khaptad and Pokhara are among a few popular mountain tourism destinations to name. The southernmost part of the country is plain called the terai with subtropical climate. Terai is also bestowed with places like Lumbini, Chitwan, Janakpur, Koshi, and many others, preferred by tourists to visit. A good number of protected areas distributed over all the physiographic provinces of the country are serving as major destinations for tourists (Aryal et al. 2019). A few examples are Chitwan National Park, Sagarmatha National Park, Annapurna Conservation area, Shivapuri Nagarjun National Park, Bardiya National Park and Shuklaphanta National Park. Rich and unique culture of approximately 26 million people in the country speaking 123 languages and practicing religions like Hinduism, Buddhism, Islam, Kirant, and Christianity, is another facet fascinating the visitors. The cultural heritage evolved over the centuries among the people of Nepal encompasses diverse ethnic, tribal and social groups and is manifested in music and dance; art and craft; folklore and folktales; languages and literatures; philosophy and religions; festivals and celebrations; religious temples and monasteries; and food and drinks. In nutshell, diverse people and their cultures supported by beautiful nature and mountainous terrain offered adventurous activities are the star attractions for tourists in the country.

\section{Methods}

A semi-structured questionnaire was developed to collect data for the survey. As the country had instituted a lockdown to tackle the situation of the global COVID-19 pandemic, in-person surveys were not possible. Additionally, it was not possible to get a countrywide response in a short period of time. Thus, online surveys were chosen as an alternative option. The study was carried out using a chain referral sampling method in which the initial respondents in different provinces were reached through social media. After the cooperation of initial respondents, they were requested to forward the form to their extended networks. The form was kept open for submission from June 12, 2020 to June 20, 2020. For this purpose, a questionnaire was devised using Microsoft forms, which consisted of two sections. The first section was dedicated 
to collecting information about the general characteristics of the respondents and the second section was designed to collect information about the travel decision immediately after the removal of restrictions. At the time of survey, as COVID-19 was a new disease with very little information available, there was great fear among the people. As COVID-19 is a contagious disease, people feared that they might get infected if they travel. Moreover, the pandemic casted impact on social and economic dimension of the society badly resulting in job loss and reduced income. Thus, to those who chose to avoid travel were asked how COVID-19 fear, poor lodging, the impact of COVID-19 on the income of respondents and their family, pressure from family, need for recovering pending work, issues of leave, and hospitality scenario would influence their choice for the avoidance of travel. Similarly, the respondents who chose to travel were asked about the motives of travel. Furthermore, they were asked to state their preferences among i) day outs, night outs and long travel; ii) location of destinations: nearby and non-nearby; and iii) popular and unexplored destinations. As the decision about the choice of the travel options are governed by economic and other contextual factors, they were asked to further clarify how fear of COVID-19, economic and issue of leave affected their travel options.

After initially sending the form through email and social media, follow-up posts and messages were done once after five days of initiation.

\section{Data management and analysis}

Once the time allocated for the survey period was over, the responses were downloaded as an excel file and the data were managed. As there were chances of double entry by the same respondents, we tallied the names and their email addresses and responses were limited to one response per respondent. Additionally, we checked whether the forms were correctly filled up. After filtering the 516 responses, we considered 506 responses for further analysis. Long questions, which were provided as the column heading by Microsoft forms, were coded to make those meaningful for further analysis.

A descriptive analysis was carried out using measures of central tendencies. Association between categorical variables was analyzed using the chi-square test, and binomial regression techniques. After chi-square test, the effect size of association was assessed using Cramer's V. Binomial logistic regression used travel agreement just after the end of the COVID-19 pandemic as a response variable and other variables (Gender, age, occupation, geographic origin and provincial address) were used as predictor variables. We started the full model and proceeded using information criteria, removing non-significant variables from the model, one at a time, until the minimum adequate model was obtained. We tested the outliers of the model using the outlier test and none of the studentized residuals with Bonferroni $\mathrm{p}<0.05$ were 
found. Model diagnostics were carried out using simulated residuals for uniformity, using the One-sample Kolmogorov-Smirnov test and dispersion tests. No significant deviation (KS test, $\mathrm{D}=0.034, \mathrm{p}=0.5896)$ and dispersion (dispersion $=1.0001, \mathrm{p}=$ $0.736)$ were observed. All analyses were done using $\mathrm{R}$ software (Version 4.0.2) ( $\mathrm{R}$ Core Team 2020), ggplot2 (Wickham 2016) was used for the graphs and DHARMa (Hartig 2020) was used for model diagnostics.

\section{Results}

The age of the respondents $(n=506)$ ranged from 14 years to 64 years (mean $=25.7$ years, $\mathrm{SD}=5.5$ ), while monthly income ranged from 0 to 1 million (mean $=57885.5$, S.D. $=71931.5$ ). The male-female ratio is slightly male-biased (Male 58.58\%), while the sample is dominated by people from the Brahmin Chhetri community (Brahmin/ Chhetri - 78.107\%, Janajati - 11.243\%, Madeshi 6.903\% and rest others) and Students (Students 64.892\%, Service 28.205\%, Business $4.535 \%$ and Other 2.367\%). The respondents from Mountain region were very less (5.52\%) while the proportion was nearly equal from Mid-hills (47.54\%) and Terai (46.94\%). The respondents were from all provinces with highest representation from Bagmati Province (Province 1 - 11.637\%, Province 2 - 7.495\%, Bagmati 34.714\%, Gandaki 17.357\%, Lumbini 12.426\%, Karnali 6.706\% and Sudurpaschim 9.665\%).

\section{Post restriction travel intention}

Of the total 506 responses used for analysis, the proportion of respondents willing to travel in-country, immediately after the travel restrictions were lifted, was exactly half. Respondents answers regarding in-country travel after COVID-19 pandemic ends were found to be marginally associated with origin $(\chi 2=5.56, \mathrm{df}=$ $2, \mathrm{p}=0.06)$ but not associated with ethnicity $(\chi 2=3.12, \mathrm{df}=3, \mathrm{p}=0.37)$, $\operatorname{gender}\left(\chi^{2}=\right.$ $0.09, \mathrm{df}=1, \mathrm{p}=0.75)$, occupation $(\chi 2=4.89, \mathrm{df}=3, \mathrm{p}=0.17)$ and provincial address $(\chi 2=6.85, \mathrm{df}=6, \mathrm{p}=0.33)$.

Age and origin significantly affected the choice of in-country visit immediately after the travel restrictions were over (Table 1).

Compared to the people of the mid-hills, the probability of the mountain people traveling is more than double. There was no significant difference between the people from the Terai and mid-hills.

Table 1: Description of major covariates relating travel preference of respondents

Coefficients Estimate Std. Error z value p-value CI.LO CI.UP

Intercept

$\begin{array}{llllll}0.94 & 0.47 & 1.97 & 0.04 & 0.018 & 1.904\end{array}$


Age

Origin.Mountain

$$
-0.036
$$

0.01

$-2.06$

$\begin{array}{lll}0.03 & -0.072 & -0.002\end{array}$

$$
0.89
$$

0.43

2.03

$0.04 \quad 0.068$

1.811

Origin.Terai

\begin{tabular}{llllll}
-0.11 & 0.18 & -0.62 & 0.53 & -0.477 & 0.246 \\
\hline
\end{tabular}

It has been found that the probability of travel after COVID-19 is significantly associated with respondent's age and area of origin. The respondents' expression of travel preference decreased by about $4 \%$ with a unit increase in year $(\beta=-0.036$, $\mathrm{z}=-2.06, \mathrm{p}=0.03)$. There were significant differences among the geographic area of origin in relation to the probability of travel after pandemic. The respondents from the mountain region showed a significantly higher probability of travel $(B=0.89, z=$ 2.03, $\mathrm{p}=0.04)$ compared to Mid-hills and Terai $(\beta=-0.11, \mathrm{z}=-0.62, \mathrm{p}=0.53)$. The respondents with origin in the mountain region were twice as likely to travel, whereas the probability of travel among the Terai origin respondents was $11 \%$ lower than to respondents of mid-hill origin (Table 1).

Figure 1: Probability of travel after restrictions are over in relation to respondent's age

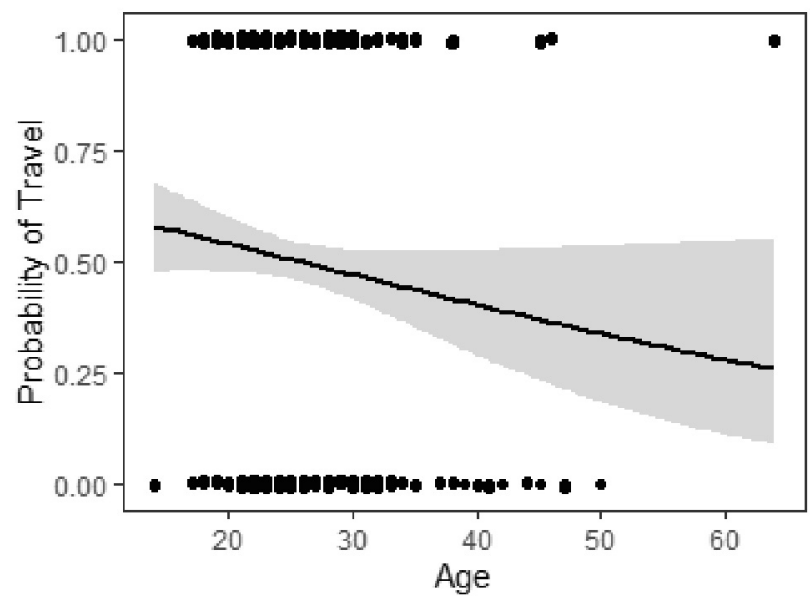

The probability of travel in the country is associated with age and geographic origin. The association is negative in the case of age (figure 1). But, if we see the same result by disaggregating age with the geographic origin, the probability to travel increases with age in Mountain region while the probability tends to decrease with age in terai and Mid-hills (figure 2). 
Figure 2: Probability of travel with respondent's age for three regions. Midhills and Terai show decrease in probability of travel with respondents' age; the case is opposite for respondents of mountain.
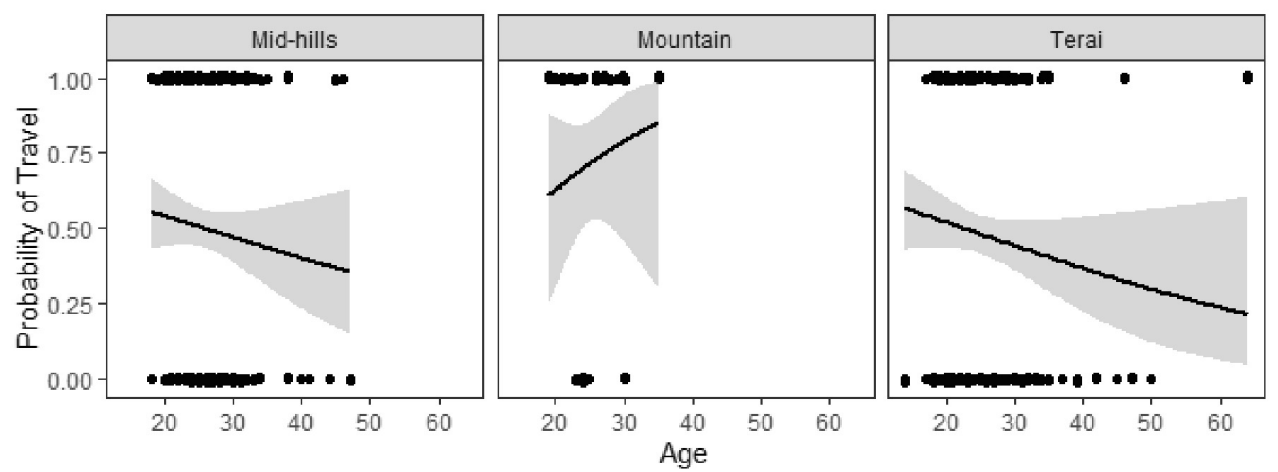

Factors Responsible for the avoidance of travel

Figure 3: Proportion of respondents in respective classes of travel avoidance. The categories ( $1=$ Not applicable, 5 totally applicable) describe the tendency of respondents to travel during post-restriction period.

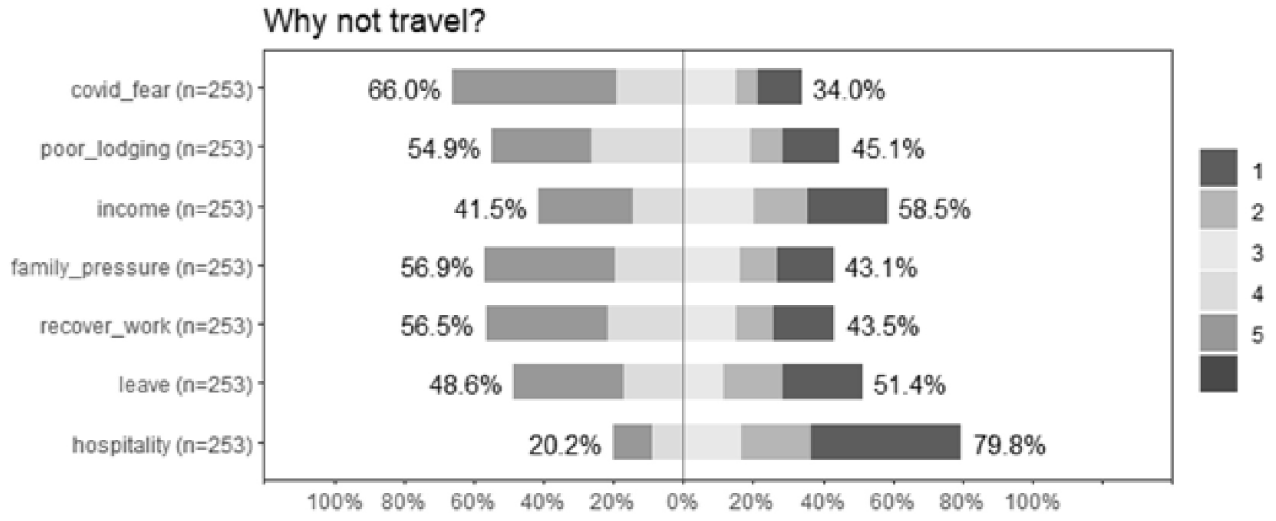

COVID-19 fear, family pressure and need of recovering the pending work were stated as the causes for avoidance of the travel immediately after the restrictions are over (Figure 3). Chance of getting leave was also an important factor, while income and hospitality were important in decisions about travel for few respondents who chose to avoid travelling. Response about the factor governing travel avoidance were found to be significantly associated. There was found to be moderate level of significant association between Covid-19 fear with the poor lodging facility $(\chi 2=149.276, \mathrm{df}=16$, 
$\mathrm{V}=0.384 \& \mathrm{p}=0.000)$. Further, COVID-19 fear, and family pressure had low level of significant association $(\chi 2=72.086, \mathrm{df}=16, \mathrm{~V}=0.267 \& \mathrm{p}=0.000)$.

\section{Motives and travel choice of those who wish to travel}

Domestic tourist preferred long tours (46.9\%) against night-outs (15\%) and only day outs (38.2\%). Refreshment (37.9\%) and motivation (26.5\%) were two leading motive for travel followed by job related travel (17\%) and refreshment and motivation combined (9.5\%). All three factors were important to $3.6 \%$ respondents while combination of refreshment and motivation with job separately were motive for $2.8 \%$ each.

Figure 4: Proportion of respondents with tendency of travel after pandemic. The categories represent the attributes of preferred travel destinations $(1=$ Not applicable, 5 totally applicable).

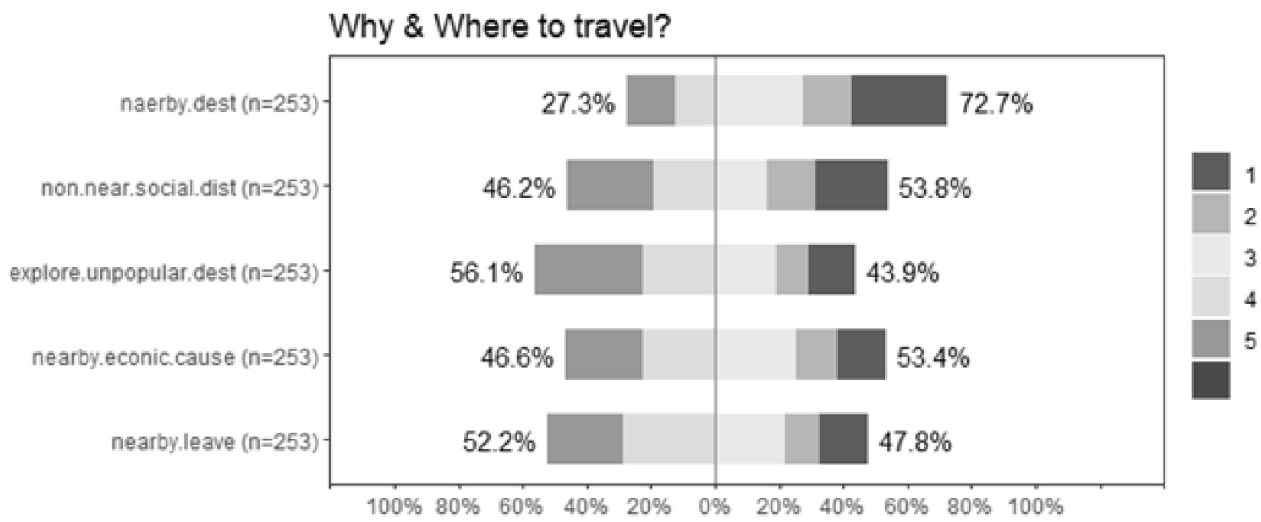

Majority of the respondents (72.7\%) disagreed on 'the nearby destinations being unsafe to travel amidst the COVID-19 pandemic'. However, the proportion of respondents who chose to avoid nearby popular destinations with the fear of COVID-19 infection due to difficulty in maintaining social distancing was almost double (46.2\%). Furthermore, most of the respondents who were willing to travel opted to explore unpopular destinations, as it would be easy to maintain social distancing and other safety measures. The preference for distant destination owing to the possibility of more safety and preference for unpopular destination owing to the ease to maintain social distancing were significantly associated $(\chi 2=80.036, \mathrm{~V}=0.281, \mathrm{p}=0.000)$. Those who chose nearby destinations opted to do so due to economic causes (finance and other resources) and issues of getting leave (Figure 4) and these two factors (economic and issue of leave) were significantly associated $(\chi 2=198.503, \mathrm{~V}=0.442, \mathrm{p}=0.000)$. Those who wished to travel immediately after restriction gets over chose to travel the popular destinations such as Pokhara, Kathmandu, Rara and Mustang (Figure 5). 
Figure 5: Word cloud of destinations where the respondents wanted to go immediately after travel restrictions are lifted

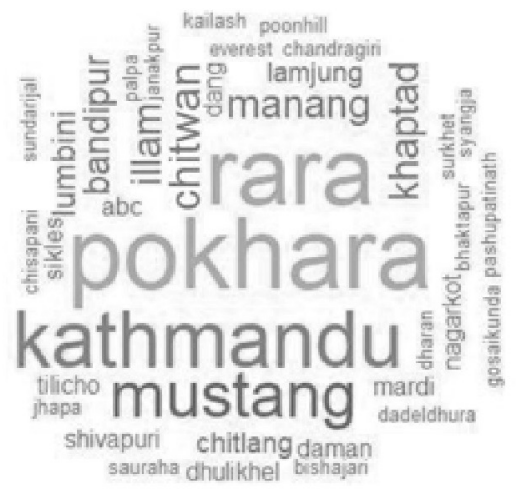

\section{Discussion}

Tourism industry in Nepal is important from economic, social and environmental perspectives. Government of Nepal has identified the industry as one of the drivers of prosperity. It provides nearly a million jobs and contributes to environment conservation and social empowerment which are well acknowledged (Chung et al. 2018; Hakim \& Soemarno 2017; Hanson et al. 2019; Panta \& Thapa 2018). However, the tourism sector of Nepal has been struck hard by the COVID-19 pandemic and inbound tourism will take time to recover. In such a scenario, in-country tourism, which is expected to return before inbound tourism (Gössling et al. 2020), has to play a pivotal role in restarting the momentum of tourism in the country. As COVID-19 was expanding rapidly and no effective vaccines were discovered when survey was conducted (July 2020), many people were reluctant to travel. In this paper, we first identified the proportion of people who wish to travel immediately after the travel restrictions are lifted, which means the confidence to travel increases. Following the reckoning, we explored the correlates of instant traveling decisions. This was followed by finding out the demotivation factors for lack of willingness to travel. We have also tried to figure out the destination choices of those who wish to travel. Furthermore, how potential visitors perceive the risk, what motivates them to travel, and what demotivates them were also explored, since these are crucial in making effective recovery plans.

\section{Post restriction travel intention}

In our survey, half of the respondents are found willing to travel immediately when travel restrictions are over. A survey done by an international payment company among the frequent visitors revealed that $70 \%$ of the respondents were willing to visit 
as soon as the pandemic was over (Flywire Corporation 2020). The study done by Flywire was focused on the respondents who used to visit more frequently, while our study involved general respondents as well, which might be the reason for the differences. Furthermore, the study by Flywire Corporation has revealed that $55 \%$ of the respondents were willing to make their visits within their own country (Flywire Corporation 2020). Domestic tourism offers a major opportunity for recovery and support for the tourism sector in the post-pandemic period (OCED 2020). Since respondents were asked about in-country travel only, we can say that the perceptions are quite similar to an extent. The social and economic characteristics of the respondents also play a pivotal role in determining their travel attitude (Kovačić et al. 2020). In case of Nepal, family pressure, economic pressure, and job and education related pressure might have increased the fractions of respondents that wish to avoid the travel during the COVID-19 pandemic.

The proportion of the mountain people willing to travel immediately after travel restrictions are over is significantly greater than the people from mid-hills and the Terai. Geography of fear (Bristow \& Jenkins 2020; Modly 2009) varies according to Eco regions as the proportion of infected persons are lower in mountain areas compared to mid- hills and Terai.

In Nepal, since the year 1992 to 2010, the trend showed that the travel age group of 31-45 has the highest share among others (Dhakal 2014; Shrestha \& Shrestha 2012). Of which $58.3 \%$ of total tourists were below the age of 45 in the year 2010 (Shrestha \& Shrestha 2012) and $30.7 \%$ of arrivals were of age 31-45 in year 2018 (MoTCA 2019). Despite of these trends in the past, the present study shows that probability of travel after COVID-19 in relation to the respondent's age shows that the probability decreases with an increase in age. However, if we disaggregate this result according to the geographic origin, the probability increases with age in Mountain region, while scenario is opposite in terai and mid-hills where younger groups have higher tendency to travel. Studies have shown that the interaction with the traveling group motivates one to travel (Bao \& Xie 2019). Though, the interaction with travellers are not explored, youths of terai and mid-hills are the ones who are most active in social media because of access to good network coverage, influencing others to travel.

\section{Factors responsible for the avoidance of travel}

COVID-19 fear among the people has been found to be the most obvious cause for the reluctance to travel. As the disease turned into a global pandemic, it is obvious to see people hesitating to travel immediately. The study conducted by Bakar and Rosbi (2020) showed that COVID-19 generates panic among the public that contributes to lower demand in the tourism industry. The fear of the coronavirus impact on tourism has been noticed in China, where Chinese tourists are banned to visit overseas nations 
(Hoque et al. 2020). A similar pattern was observed during other epidemics as well. The virus outbreak of Middle East Respiratory Syndrome (MERS) in South Korea in 2015 provoked fear, which resulted in a mass reduction in transit use and travel behavior, where fear had a significant influence on travel with a reduction in trip frequency (Kim et al. 2017). Perceived control, theory of extended planned behavior and health belief model can explain these choices about the decisions (Abraham \& Sheeran 2007; Chen \& Tung 2014; Wallston 2007). Family pressure also describes the reluctance to travel immediately after the restrictions are over. The decision of travel in this sort of scenario is governed not only by the risk perceived by the individuals, but also the opinion by family is also equally important. Additionally, a significant number of the respondents feared about the chances of getting infected due to poor lodging facilities and transportation.

In order to resume tourism for the survival of the industry and also to ensure safety to the tourists, industry and public; the Government of Nepal (GoN) has come up with COVID-19 safety and hygiene protocol for the Tourism Industry. The protocol is for different sectors of tourism which aims to support the industry in gaining back momentum and come out of the crisis on a phase of new normal of health, hygiene, and sanitation (GoN/MoCTCA/NTB 2020). To remove fear, the protocol needs to be effectively communicated to all stakeholders including visitors and implement them strictly.

Furthermore, the need to recover work or studies that are pending due to restrictions also explained the reluctance to travel in the post restriction period. It is because majority of the respondents in our survey are students and the final exam of majority of the students were postponed due to implementation of lockdown. In Nepal long holidays are provided in October-November (depends on lunar calendar) during Dashain and Tihar (major festivals of Hindu Community, which represents nearly $85 \%$ of population of the country) (Neupane 2019). Due to this, seasonal upsurge of tourist, popular tourism destinations cannot provide adequate facilities. Domestic tourists often complain about the hospitality offered to them compared to that of in-bound tourists in Nepal particularly in popular tourist destinations (Bista 2009) such as Annapurna Conservation Area region, but for post restriction period, respondents do not perceive that to be a significant demotivating factor.

\section{Motives and travel choice of those who wish to travel}

The proportions of the respondents who have chosen the long tours are greater than those who have chosen a day outs and night tours and push factor such as refreshment and motivation has been the main reason to travel. The finding is consistent to the other studies which have indicated that the escape to be the major push factor for the tourist (Nikjoo \& Ketabi 2015). COVID-19 and restrictions 
imposed subsequently have cast psychological impacts to the Nepalese people in addition to the economic and social impacts (Poudel \& Subedi 2020). This could be attributed to the higher preferences for refreshment among the respondents.

Respondents willing to visit the nearby destination opted to avoid more popular destinations with the fear of getting infected with COVID-19 in highly visited places. This fear factor has provided a unique opportunity of promoting the new destination for tourism and offering diversification in services. In the past, diversification of the products and destinations were identified as essential for post crisis recovery of tourism (Beirman et al. 2018). Nearer destinations may be chosen as economizing strategies (Campos-Soria et al. 2015).

Immediately after restrictions are over, social distancing is expected to be a social norm. Those willing to engage in long tours have also opted to explore the unpopular destination as they are less frequently visited by the people and will ease to maintain social distancing thereby minimizing contact. Exploring and promoting new destinations would do in that regard. Popular tourism destinations in Nepal such as Pokhara, Kathmandu, Mustang and Rara (MoTCA 2019) were chosen by majority of the respondents on the contrary to the original statement. The fraction of the respondents from Kathmandu, Pokhara and nearby was more which might explain this contradiction. Leave and economic reasons might have also forced respondents to choose nearby destinations. In such a case, paid leave for the employee by the government and employer could serve dual purpose of redistribution of the income to the rural and novel destinations, and motivation and refreshment for the workers. Domestic tourism activities were reported to upsurge in China in response to different paid holiday schemes introduced (Shen et al. 2018).

COVID-19 pandemic though has impacted the tourism sector in the short run, it has also provided an opportunity to make transformation on our business approach in new direction and step forward setting a more sustainable path (Ioannides \& Gyimóthy 2020; Nepal 2020) that includes the search for traditionally undervalued markets such as domestic tourism (Brouder 2020). Diversity in the products is essential to develop the domestic tourism (Morupisi \& Mokgalo 2017). For Nepal, diversification of the products and destinations were identified as essential strategies in the past for post crisis recovery of tourism (Beirman et al. 2018). The less popular destinations such as Khaptad might raise issues of hospitality due to low level of infrastructure like hotels and transport services. However, addressing internal tourists' choices will open potential of new tourism destination and product development. Concerned stakeholders including the local governments should consider integrating the locally available environmental and cultural components of the surrounding to develop new products that can be offered to domestic tourists in a post pandemic situation. 
Tourism industry was gradually growing in Nepal in the pre-pandemic situation as indicated by the tourist numbers and contribution in gross domestic product. However, the Industry of Nepal is profoundly stricken by the COVID-19 pandemic and the international tourism will take time to recover. To make the tourism industry ready to welcome guests, when the situation gets normalized, the services and manpower needs to be operational in the transition phase. Without some income from tourism or support from the government, many tourisms related businesses will not survive. Though the inbound tourism activities are expected to return a bit late, our result indicates that nearly half of the domestic tourists are willing to travel immediately after the travel and other restrictions are lifted. If the concerns for safety issues are addressed, more people can join the early travellers. Furthermore, there are unique opportunities to bring new destinations and products into the new scenario after COVID-19 pandemic ends.

\section{Acknowledgements}

This research work was possible with the generous support of diverse arrays of people. We would like to thank all the respondents who provided a valuable response in a short time. Furthermore, we would like to thank Mr. Shyam Shrestha, Naresh Kumar Mahato, Bishal Sharma and all those who directly helped in data collection. Furthermore, we are indebted towards our colleague at Environment Protection and Study Center who helped in different stage of study. We are thankful to the anonymous reviewers whose suggestion helped to improve the quality of this work.

\section{Declaration of conflict of interest}

Authors would like to declare no conflict of interest.

\section{References}

Abraham, C., \& Sheeran, P. (2007). The health belief model. In Cambridge Handbook of Psychology, Health and Medicine, Second Edition (pp. 97-102). https://doi. org/10.1017/CBO9780511543579.022

Adler, C. E., McEvoy, D., Chhetri, P., \& Kruk, E. (2013). The role of tourism in a changing climate for conservation and development. A problem-oriented study in the Kailash Sacred Landscape, Nepal. Policy Sciences, 46(2), 161-178. https:// doi.org/10.1007/s11077-012-9168-4

Aryal, C., Ghimire, B., \& Niraula, N. (2019). Tourism in Protected Areas and Appraisal of Ecotourism in Nepalese Policies. Journal of Tourism \& Hospitality Education, 9, 40-73. https://doi.org/10.3126/jthe.v9i0.23680

Basnyat, S., Shrestha, S., Shakya, B., Byanjankar, R., \& Basnyat, S. (2020). Domestic Tourism in Nepal: Issues and Challenges. Tourism Review International, 24(1), 37-49. 
Bista, R. (2009). Tourism Policy, Possibilities and Destination Service Quality Management in Nepal. http://www.docin.com/p-319631690.html

Grančay, M. (2020). Tourism sector in New Zealand-demand-side measures are necessary. New Zealand Economic Papers. https://doi.org/10.1080/00779954.2020.1844787

Hussain, A., \& Fusté-Forné, F. (2021). Post-Pandemic Recovery: A Case of Domestic Tourism in Akaroa (South Island, New Zealand). World, 2(1), 127-138. https:// doi.org/10.3390/world2010009

MoTCA. (2020). Nepal Tourism Statistics 2019. Government of Nepal, Ministry of Culture, Tourism \& Civil Aviation. https://www.tourism.gov.np/files/NOTICE MANAGER_FILES/Nepal_tourism_statics_2019.pdf

Rastegar, R., Higgins-Desbiolles, F., \& Ruhanen, L. (2021). COVID-19 and a justice framework to guide tourism recovery. Annals of Tourism Research, $x x x x, 103161$. https://doi.org/10.1016/j.annals.2021.103161

Bao, J., \& Xie, H. J. (2019). Determinants of Domestic Tourism Demand for Guilin. Journal of China Tourism Research, 15(1), 1-14. https://doi.org/10.1080/1938816 0.2018 .1515139

Beirman, D., Upadhayaya, P. K., Pradhananga, P., \& Darcy, S. (2018). Nepal tourism in the aftermath of the April/May 2015 earthquake and aftershocks: repercussions, recovery and the rise of new tourism sectors. Tourism Recreation Research, 43(4), 544-554. https://doi.org/10.1080/02508281.2018.1501534

Bhattarai, K., Conway, D., \& Shrestha, N. (2005). Tourism, terrorism and turmoil in Nepal. Annals of Tourism Research, 32(3), 669-688. https://doi.org/10.1016/j. annals.2004.08.007

Bristow, R. S., \& Jenkins, I. S. (2020). Geography of fear: fright tourism in urban revitalization. Journal of Policy Research in Tourism, Leisure and Events, 12(2), 262-275. https://doi.org/10.1080/19407963.2019.1631319

Brouder, P. (2020). Reset redux: possible evolutionary pathways towards the transformation of tourism in a COVID-19 world. Tourism Geographies, 22(3), 484-490. https://doi.org/10.1080/14616688.2020.1760928

Campos-Soria, J. A., Inchausti-Sintes, F., \& Eugenio-Martin, J. L. (2015). Understanding tourists' economizing strategies during the global economic crisis. Tourism Management, 48(February 2018), 164-173. https://doi.org/10.1016/j. tourman.2014.10.019

Chen, M. F., \& Tung, P. J. (2014). Developing an extended Theory of Planned Behavior model to predict consumers' intention to visit green hotels. International Journal of Hospitality Management, 36, 221-230. https://doi.org/10.1016/j.ijhm.2013.09.006 
Chinazzi, M., Davis, J. T., Ajelli, M., Gioannini, C., Litvinova, M., Merler, S., Pastore Y Piontti, A., Mu, K., Rossi, L., Sun, K., Viboud, C., Xiong, X., Yu, H., Halloran, M. E., Longini, I. M., \& Vespignani, A. (2020). The effect of travel restrictions on the spread of the 2019 novel coronavirus (COVID-19) outbreak. Science (New York, N.Y.), 9757(March), 1-12. https://doi.org/10.1126/science.aba9757

Chung, M. G., Dietz, T., \& Liu, J. (2018). Global relationships between biodiversity and nature-based tourism in protected areas. Ecosystem Services, 34(September), 11-23. https://doi.org/10.1016/j.ecoser.2018.09.004

Cohen, J., \& Kupferschmidt, K. (2020). Countries test tactics in 'war' against COVID-19. Science, 367(6484), 1287-1289.

Dhakal, K. R. (2014). An Analysis of the Tourism in Nepal Trend of Tourist Arrivals. The Third Pole: Journal of Geography Education, 13, 46-53. https:/doi.org/10.3126/ ttp.v13i0.11546

Flywire Corporation. (2020). Flywire Survey Reveals Consumers Upbeat About Travel Post COVID-19. https://www.globenewswire.com/newsrelease/2020/06/16/2048726/0/en/Flywire-Survey-Reveals-Consumers-UpbeatAbout-Travel-Post-COVID-19.html

GoN/MoCTCA/NTB. (2020). Operational Guideline with Health Protocol for Tourism Sector (1st ed.). Government of Nepal, Ministry of Culture, Tourism and Civil Aviation, Nepal Tourism Board.

Gössling, S., Scott, D., \& Hall, C. M. (2020). Pandemics, tourism and global change: a rapid assessment of COVID-19. Journal of Sustainable Tourism, 0(0), 1-20. https://doi.org/10.1080/09669582.2020.1758708

Hakim, L., \& Soemarno, M. (2017). Biodiversity conservation, community development and geotourism development in Bromo-Tengger-Semeru-Arjuno biosphere reserve, East Java. Geojournal of Tourism and Geosites, 20(2), 220-230.

Hall, C. M., Scott, D., \& Gössling, S. (2020). Pandemics, transformations and tourism: be careful what you wish for. Tourism Geographies, 0(0), 1-22. https://doi.org/10. 1080/14616688.2020.1759131

Hanson, J. H., Schutgens, M., \& Baral, N. (2019). What explains tourists' support for snow leopard conservation in the Annapurna Conservation Area, Nepal? Human Dimensions of Wildlife, 24(1), 31-45. https://doi.org/10.1080/10871209.2019.153 4293

Hartig, F. (2020). DHARMa: residual diagnostics for hierarchical (multi-level/mixed) regression models. $R$ package version 0.3.3.0. 
Hoque, A., Shikha, F. A., Hasanat, M. W., Arif, I., \& Abu Bakar Abdul Hamid. (2020). The Effect of Coronavirus ( COVID-19) in the Tourism Industry in. Asian Journal of Multidisciplinary Studies, 3(1).

Ioannides, D., \& Gyimóthy, S. (2020). The COVID-19 crisis as an opportunity for escaping the unsustainable global tourism path. Tourism Geographies, 22(3), 624632. https://doi.org/10.1080/14616688.2020.1763445

Kabote, F., Mamimine, P. W., \& Muranda, Z. (2017). Domestic tourism for sustainable development in developing countries. African Journal of Hospitality, Tourism and Leisure, 6(2), 1-12.

Kim, C., Cheon, S. H., Choi, K., Joh, C. H., \& Lee, H. J. (2017). Exposure to fear: Changes in travel behavior during MERS outbreak in Seoul. KSCE Journal of Civil Engineering, 21(7), 2888-2895. https://doi.org/10.1007/s12205-017-0821-5

Kovačić, S., Margarint, M. C., Ionce, R., \& Miljković, D. (2020). What are the factors affecting tourist behavior based on the perception of risk? Romanian and Serbian tourists' perspective in the aftermath of the recent floods and wildfires in Greece. Sustainability (Switzerland), 12(16). https://doi.org/10.3390/SU12166400

Li, H., Meng, F., \& Zhang, Z. (2016). Non-participation of Domestic Tourism: Analyzing the Influence of Discouraging Factors. International Journal of Tourism Research, 18(6), 567-578. https://doi.org/10.1002/jtr.2074

Llorca-Rodríguez, C. M., García-Fernández, R. M., \& Casas-Jurado, A. C. (2020). Domestic versus inbound tourism in poverty reduction: evidence from panel data. Current Issues in Tourism, 23(2), 197-216. https://doi.org/10.1080/136835 00.2018.1494701

McKibbin, W., \& Fernando, R. (2020). The Global Macroeconomic Impacts of COVID-19: Seven Scenarios. In CAMA Working Paper (19/2020; CAMA Working Paper).

Modly, A. R. (2009). Geography of Fear: Understanding Students' Sense of Place. Annual Review of Undergraduate Research, 8, 115-146. http://chrestomathy.cofc. edu/documents/vol8/modly.pdf

Morupisi, P., \& Mokgalo, L. (2017). Domestic tourism challenges in Botswana: A stakeholders' perspective. Cogent Social Sciences, 3(1). https://doi.org/10.1080/23 311886.2017.1298171

MoTCA. (2019). Nepal Tourism Statistics 2018,

Nepal, S. K. (2020). Adventure travel and tourism after COVID-19-business as usual or opportunity to reset? Tourism Geographies, 22(3), 646-650. https://doi.org/10. $1080 / 14616688.2020 .1760926$ 
Neupane, P. C. (2019). Destination Management: Nepalese Efforts, Experience \& Challenges. The Gaze: Journal of Tourism and Hospitality, 10, 51-66.

Nikjoo, A. H., \& Ketabi, M. (2015). The role of push and pull factors in the way tourists choose their destination. Anatolia, 26(4), 588-597. https://doi.org/10.10 80/13032917.2015.1041145

OCED. (2020). Tourism Policy Responses to the coronavirus (COVID-19). https:// www.oecd.org/coronavirus/policy-responses/tourism-policy-responses-to-thecoronavirus-covid-19-6466aa20/

Panta, S. K., \& Thapa, B. (2018). Entrepreneurship and women's empowerment in gateway communities of Bardia National Park, Nepal. Journal of Ecotourism, 17(1), 20-42. https://doi.org/10.1080/14724049.2017.1299743

Poudel, K., \& Subedi, P. (2020). Impact of COVID-19 pandemic on socioeconomic and mental health aspects in Nepal. International Journal of Social Psychiatry, 66(8), 748-755. https://doi.org/10.1177/0020764020942247

R Core Team. (2020). R: A Language and Environment for Statistical Computing. $R$ Foundation for Statistical Computing, 1(4.0.2), 409. https://doi.org/10.1007/9783-540-74686-7

Ruiz Estrada, M. A., Park, D., \& Lee, M. (2020). The Evaluation of the Final Impact of Wuhan COVID-19 on Trade, Tourism, Transport, and Electricity Consumption of China. SSRN Electronic Journal, 1-13. https://doi.org/10.2139/ssrn.3551093

Sharma, P. (2012). Tourism in Nepal 2030. In S. R. Sharma, B. R. Upreti, \& K. Pyakuryal (Eds.), Nepal 2030: A Vision for Peaceful and Prosperous Nation (pp. 73-92). South Asia Regional Coordination Office of the Swiss National Centre of Competence in Research (NCCR North-South) and Department of Development Studies, Kathmandu University.

Shen, H., Wang, Q., Ye, C., \& Liu, J. S. (2018). The evolution of holiday system in China and its influence on domestic tourism demand. Journal of Tourism Futures, 4(2), 139-151. https://doi.org/10.1108/JTF-10-2016-0027

Shrestha, H. P., \& Shrestha, P. (2012). Tourism in Nepal: A Historical Perspective and Present Trend of Development. Himalayan Journal of Sociology \& Antropology, V, 54-75.

Shrestha, R., Shrestha, S., Khanal, P., \& Bhuvan, K. C. (2020). Nepal's First Case of COVID-19 and public health response. Journal of Travel Medicine, February, 1-6. https://doi.org/10.1093/jtm/taaa024

Thapa, B. (2003). Tourism in Nepal Tourism in Nepal : Shangri-La's Troubled Times. Journal of Travel \& Tourism Marketing, 15(2), 117-138. https://doi.org/10.1300/ J073v15n02 
UN DESA. (2018). UN list of Least Developed Countries. https://www.un.org/ development/desa/dpad/least-developed-country-category/ldcs-at-a-glance. html

UNWTO. (2020). Tourism and COVID-19. World Tourism Organization (UNWTO).

Upadhayaya, P. K., Müller-Böker, U., \& Sharma, S. R. (2011). Tourism amidst Armed Conflict: Consequences, Copings, and Creativity for Peace-building through Tourism in Nepal. The Journal of Tourism and Peace Research, 1(2), 22-40. https:// doi.org/10.5167/uzh-42464

Wallston, K. A. (20007). Perceived control. In Cambridge Handbook of Psychology, Health and Medicine, Second Edition (pp. 148-150). https://doi.org/10.1017/ CBO9780511543579.032

WHO. (2020). Coronavirus (COVID-19) events as they happen. https://www.who.int/ emergencies/diseases/novel-coronavirus-2019/events-as-they-happen

Wickham, H. (2016). ggplot2: Elegant Graphics for Data Analysis. Springer-Verlag New York. http://ggplot2.org

WTTC. (2020a). Travel \& Tourism Economic Impact 2019 World

WTTC. (2020b). Travel \& Tourism: Economic impact 2019 Nepal.

Zenker, S., \& Kock, F. (2020). The coronavirus pandemic - A critical discussion of a tourism research agenda. Tourism Management, 81(January), 104164. https:// doi.org/10.1016/j.tourman.2020.104164 